\title{
A LIBERDADE ACADÊMICA NA EDUCAÇÃO EM DIREITOS HUMANOS NO ENSINO JURÍDICO: UMA PROPOSTA A PARTIR DA TRANSVERSALIDADE
}

\author{
Alexandre Magno Augusto Moreira ${ }^{1}$
}

\section{Resumo:}

O presente artigo analisa o estudo da liberdade acadêmica na educação em direitos humanos no ensino jurídico, sob a perspectiva do estudo transversal. Observa-se o direito fundamental à educação, a liberdade de ensinar e acadêmica através de seus fundamentos, a educação em direitos humanos geral, no ensino jurídico, para então, se discorrer o tema proposto. A pesquisa desenvolve-se pelo método dedutivo, revisão bibliográfica, e a legislação internacional, nacional e atos normativos secundários. Conclui-se, na aplicação da transversalidade como ferramenta pedagógica hábil no ensino superior jurídico na educação em direitos humanos, obediente aos princípios da liberdade de ensinar e aprender.

Palavras-chave: Direito à Educação; Liberdade Acadêmica; Educação em Direitos Humanos; Ensino Jurídico; Transversalidade.

\section{ACADEMIC FREEDOM IN HUMAN RIGHTS EDUCATION IN LEGAL EDUCATION: A PROPOSAL FROM TRANSVERSALITY}

\begin{abstract}
:
This article analyzes the study of academic freedom in human rights education in legal education, from the perspective of cross-sectional study. We observe the fundamental right to education, the freedom to teach and academic through its foundations, education in general human rights, in legal education, so that the proposed theme can be discussed. The research is carried out by the deductive method, bibliographic review, and international, national legislation and secondary normative acts. In conclusion, in the application of transversality as a skillful pedagogical tool in higher legal education in human rights education, obedient to the principles of freedom to teach and learn.
\end{abstract}

Keywords: Right to education; Academic Freedom; Human Rights Education; legal education; Transversality;

\section{INTRODUÇÃO}

O presente artigo pretende realizar uma abordagem acerca da liberdade acadêmica na educação em direitos humanos, utilizando-se como proposta, o estudo a partir da transversalidade.

\footnotetext{
${ }^{1}$ Doutorando em Direito Empresarial e Cidadania pelo Centro Universitário Curitiba - UNICURITIBA. Mestre em Direito Processual Civil e Cidadania-UNIVERSIDADE PARANAENSE-UNIPAR-Unidade-Francisco Beltrão - PR. Coordenador/Professor do Curso de Direito da UNIPAR - Unidade de Francisco Beltrão - PR. Email: alexandremagno@ prof.unipar.br.
} 
Neste sentido, como premissa de análise, buscar-se-á tratar do direito à educação como direito fundamental social no Estado Democrático de Direito, utilizando-se como fundamento, a Constituição Federal e demais dispositivos pertinentes.

Em ato contínuo, pretende-se tratar do direito constitucional da liberdade de ensinar, sob o aspecto da reciprocidade entre as liberdades de aprender e ensinar, com enfoque na autonomia das Instituições de Ensino Superior, obedientes a prática inseparável entre pesquisa, ensino e extensão.

Ademais, desenvolver-se-á uma abordagem sobre a liberdade acadêmica, adotandose posicionamentos de sua relação ou divergência conceitual com a liberdade de ensinar, demonstrando-se no contexto, a relação da atividade docente proativa e participativa, em concomitância ao direito reflexivo do aluno na discussão do processo de ensinoaprendizagem.

$\mathrm{Na}$ sequência, permite-se discorrer brevemente sobre a educação em direitos humanos, e, como corolário da discussão proposta no trabalho, a educação em direitos humanos no ensino superior jurídico.

Por derradeiro, diante de uma pesquisa utilizada sobre o método dedutivo, com revisão bibliográfica através de teorias do direito, legislação internacional e nacional, pretende-se apresentar uma proposta do uso da transversalidade na educação em direitos humanos no ensino superior jurídico.

\section{O DIREITO FUNDAMENTAL/SOCIAL À EDUCAÇÃO}

A educação é retratada como direito social, de segunda geração ${ }^{2}$, qualificada como uma prestação positiva a ser realizada pelo $E \operatorname{stado}^{3}$, direito fundamental devidamente inserido no Título II da Constituição Federal de 1988.

O direito à educação encontra-se positivado como norma fundamental na disposição

\footnotetext{
${ }^{2}$ Os direitos de segunda geração merecem um exame mais amplo. Dominam o século XX do mesmo modo como os direitos de primeira geração dominaram o século passado. São os direitos sociais, culturais e econômicos bem como os direitos coletivos ou de coletividades, introduzidos no constitucionalismo das distintas formas de Estado social, depois que germinaram por obra da ideologia e da reflexão antiliberal do século XX. Nasceram abraçados ao princípio da igualdade, do qual não se podem separar, pois fazê-lo equivaleria a desmembrá-los da razão de ser que os ampara e estimula. (BONAVIDES, 2010, p. 564).

${ }^{3}$ Denominação dada por José Afonso da Silva como "dimensão dos direitos fundamentais do homem, são prestações positivas proporcionadas pelo Estado direta ou indiretamente, enunciadas em normas constitucionais, que possibilitam melhores condições de vida aos mais fracos, direitos que tendem a realizar a igualização de situações sociais desiguais". (SILVA, 2011, p. 286).
} 
do artigo $6^{\circ}$ da Constituição Federal. Para justificar a natureza social do direito à educação, o artigo $1^{\circ}$ da Constituição é incisivo ao afirmar que a República Federativa é constituída de um Estado Democrático de Direito, tendo como fundamentos a cidadania, o pluralismo político, os valores sociais do trabalho e da livre iniciativa e a soberania popular.

Em complemento ao artigo $6^{\circ}$ da Constituição Federal, a prescrição constitucional do artigo 205 deixa clarividente o direito à educação como direito de todos, e, em consequência, dever do Estado e da família. Neste raciocínio importa esclarecer que:

\footnotetext{
“O art. 205 contém uma declaração fundamental que, combinada com o art. $6^{\circ}$, eleva a educação ao nível dos direitos fundamentais do homem. (...) A norma assim explicitada - "A educação, direito de todos e dever do Estado e da família [...]" (arts. 205 e 227) -, significa, em primeiro lugar, que o Estado tem que aparelhar-se para fornecer, a todos, os serviços educacionais, isto é, oferecer ensino, de acordo com os princípios estatuídos na Constituição (art. 206); que ele tem que ampliar cada vez mais as possibilidades de que todos venham a exercer igualmente esse direito; e, em segundo lugar que todas as normas da Constituição, sobre educação e ensino, hão que ser interpretadas em função daquela declaração e no sentido de sua plena e efetiva realização”. (SILVA, 201, p. 313-314).
}

Ademais, a natureza social do Estado democrático de direito se manifesta explicitamente com o princípio fundamental da dignidade da pessoa humana, de forma que, a concepção social democrática que encarta a Constituição Federal requer na prática, não apenas o respeito aos direitos individuais (liberdade, direito de ir e vir), mas também, o respeito aos direitos sociais (trabalho, saúde), dos quais destacam-se na problematização em apreço, o direito a educação. (DUARTE, 2007, p. 694).

Tamanha a importância do tema tratado de natureza constitucional, reflete-se a proteção do direito à educação em normativas internacionais, em destaque, a Declaração Universal de Direitos Humanos (artigo XXVI), o Pacto Internacional sobre Direitos Econômicos, Sociais e Culturais (artigo 13), a Convenção sobre a Eliminação de todas as formas de Discriminação Racial (artigo VII), a Convenção sobre a Eliminação de todas as formas de Discriminação contra a Mulher (artigo 10), com ênfase no direito à educação de forma indiscriminada.

A norma infraconstitucional trata do tema com grande importância, fruto da força atribuída ao direito à educação como norma fundamental, na forma de execução normativa as 
diretrizes dispostas pelas normas fundamentais. Neste sentido, citam-se a Lei de Diretrizes e Bases da Educação Nacional (Lei n. 9.394 de 1996), o Estatuto da Criança e do Adolescente (Lei 8.069 de 1990) e o Plano Nacional de Educação (Lei 10.172 de 2001).

Em razão de todo o exposto, observa-se que o direito à educação é um direito fundamental concedido a todo cidadão, posto que, o Estado tem o dever da respectiva prestação positiva de forma ampla, com fins a atender o maior número de pessoas, obediente aos fundamentos e objetivos propostos pelo texto constitucional, dos quais destacam-se a dignidade da pessoa humana, a cidadania e a busca pela construção de uma sociedade livre e solidária, garantindo o desenvolvimento da nação.

\section{A LIBERDADE DE ENSINAR: CONTEXTUALIZAÇÃO CONSTITUCIONAL}

Antes de se adentrar a liberdade de ensinar enquanto tratamento constitucional, importa ilustrar o conceito fundamental do termo liberdade. A expressão liberdade é retratada por Hayek (1983, p. 27) “como o estado no qual o homem não está sujeito a coerção pela vontade arbitrária de outrem", intitulada pelo autor como liberdade pessoal ou individual. Significa dizer, portanto, a esfera privada de atuação do indivíduo, sem que haja qualquer interferência por parte de outro indivíduo, de forma que, a liberdade é violada, diante da manifesta coerção volitiva arbitrária de outrem.

Respectiva expressão ${ }^{4}$ é tratada dentro da amplitude constitucional do direito fundamental à educação, mais especificadamente no título VIII, capítulo III, seção I, nos termos dos artigos 206, 207 e 209.

As especificidades do artigo 206 da Constituição Federal retratam os princípios gerais dos quais a educação deva ser executada, neles se destacando, a igualdade de condições

\footnotetext{
${ }^{4}$ A liberdade é classificada por José Afonso da Silva dentro de suas formas, buscando tratar da expressão no plural, como liberdades, tipificada como várias expressões de liberdade, distinguindo em cinco grandes grupos, dos quais, em destaque ao tema proposto no artigo, vale o destaque ao "item 5": (1) liberdade da pessoa física (liberdades de locomoção, de circulação); (2) liberdade de pensamento, com todas as suas liberdades (opinião, religião, informação, artística, comunicação do conhecimento); (3) liberdade de expressão coletiva em suas várias formas (de reunião, de associação); (4) liberdade de ação profissional (livre escolha e de exercício de trabalho, ofício e profissão); (5) liberdade de conteúdo econômico e social (liberdade econômica, livre iniciativa, liberdade de comércio, liberdade ou autonomia contratual, liberdade de ensino e liberdade de trabalho), de que trataremos entre os direitos econômicos e sociais, porque não integram o campo dos direitos individuais, mas o daqueles. (SILVA, 2011, p. 235).
} 
para o acesso $^{5}$ e permanência na escola, a liberdade de aprender e ensinar, pesquisar e divulgar o pensamento, o pluralismo de ideias e concepções pedagógicas, garantindo a coexistência de instituições de ensino público e privada e o ensino público em estabelecimentos oficiais de forma gratuita. (BRASIL, 1988).

Sobre este contexto:

\begin{abstract}
A liberdade de ensinar, assim como os demais direitos fundamentais, deve ser exercida de forma legitima e coerente com o ordenamento jurídico-constitucionaldemocrático ao qual se encontra inserida. Ou seja, a liberdade de cátedra não pode ser vista como o direito de o docente dizer, ensinar e impor unilateralmente o que acredita, ignorando os fundamentos científicos. Além da abertura ao debate crítico, o docente precisa estar disposto constantemente a revisitar sua forma de compreender, ler e analisar as proposições cientificas preexistentes. (COSTA, 2018, p. 383).
\end{abstract}

Em complemento, o artigo 207 da Constituição Federal destaca a liberdade de ensinar sobre a perspectiva da autonomia universitária (RODRIGUES; MAROCCO, 2014, p. 4), quando prescreve que as universidades gozam de autonomia didático-científica, administrativa e de gestão financeira e patrimonial, com obediência ao critério inseparável entre pesquisa, extensão e ensino. (BRASIL, 1988).

Para ilustrar, respectiva autonomia ${ }^{6}$ pode ser analisada sob o ponto de vista da liberdade das instituições de ensino superior na criação de cursos, cabendo então ao Poder Público, como órgão fiscalizador, o dever de avaliar periodicamente as instituições e respectivos cursos, o que torna, portanto, inexigível qualquer autorização prévia para a criação de cursos. (RODRIGUES, 2012, p. 10). Outrossim, Rodrigues (2012) complementa pela necessária existência de condições prévias para o alcance da respectiva autonomia na abertura de cursos, quais sejam, a autorização prévia, de acordo com as normativas existentes para atuar como universidade, a indissociabilidade entre a pesquisa, o ensino e a extensão, e, por

\footnotetext{
${ }^{5}$ Neste sentido: É importante ressaltar, para concluir, que as normas educacionais, de forma geral, devem ser interpretadas no sentido de garantir o acesso (ingresso inicial e reingresso) e, uma vez assegurado esse acesso, garantir a permanência do aluno no sistema e mesmo a sua reintegração. Qualquer interpretação que contrarie esse grande princípio, que permeia todo o Direito Educacional brasileiro, não deve ser considerada. (RODRIGUES, 2006, p. 206).

${ }^{6} \mathrm{O}$ termo autonomia enquanto significado muito se confunde com a expressão soberania, uma vez que se traduz pela capacidade de reger-se por leis próprias. A palavra autonomia perde a característica de absoluta, quando então é vista sob a esfera de uma instituição pertencente ao Estado. As instituições existem, são criadas por Lei, mas atuam de forma legitimada, nos exatos termos que foram propostas. Desta forma, a autonomia institucional é sempre relativa, e caracterizada na medida de suas próprias normas, em cumprimento aos fins sociais para as quais se destina. (...) Em consequência disto, a autonomia universitária é exercer as suas atribuições dentro das normas estabelecidas, não eximindo as instâncias públicas superiores, da fiscalização efetiva quanto a correta prestação dos serviços. (DURHAM, 1989, p. 1-2).
} 
fim, a submissão periódica de avaliações pelo poder público, com vias a manutenção na qualidade do ensino.

Aliada as demais disposições constitucionais, a liberdade de ensinar encontra-se positivada no artigo 209 da Constituição Federal, em seus incisos I e II, do qual destaca que o ensino é livre a iniciativa privada, desde que haja o respeito e cumprimento as normas gerais da educação nacional, a autorização e avaliação de qualidade pelo Poder Público. (BRASIL, 1988).

A disposição acima transcrita se refere tão exclusivamente as instituições de ensino privadas, no entanto, vale ressaltar que respectivas condições se estendem as instituições públicas, imposição implícita, vez que, antes de se exigir da instituição privada, coerente que se faça o dever de casa (exigir de si mesmo), em razão da natureza pública que constitui a educação. (RODRIGUES; MAROCCO, 2014, p. 5-6).

Portanto, a liberdade de ensinar encontra-se disseminada no texto constitucional sobre vários aspectos, admitindo-se a coexistência de instituições público e privadas, aliado ao direito constitucional de autonomia das instituições de ensino, respeitando o caráter indissociável da pesquisa, da extensão e do ensino, desde que, obedientes as normas educacionais, atendendo ao padrão de qualidade na educação, comprovado por avaliações periódicas realizadas pelo Poder Público.

\subsection{A LIBERDADE ACADÊMICA: PERSPECTIVAS PARA UMA CONSTRUÇÃO REFLEXIVA ENTRE DOCENTES E DISCENTES}

Como premissa de estudo do tema, indispensável estabelecer um aporte teórico histórico, no que diz respeito à liberdade de cátedra ${ }^{7}$ como previsão constitucional.

A Constituição Republicana de 1934 foi precursora ao tratar do tema liberdade de cátedra, na disposição do artigo 155 de forma sucinta ao prescrever que a "é garantida a liberdade de cátedra". (BRASIL, 1934).

\footnotetext{
${ }^{7}$ As expressões, liberdade acadêmica e liberdade de cátedra podem trazer confusão ao leitor, no entanto, esclarece-se: A expressão pode ser compreendida em conjunto, como a liberdade acadêmica docente de ensinar (RODRIGUES; OLIVEIRA, 2019, p. 165), e, por outro lado, posiciona-se a expressão liberdade de ensinar como parte restrita da liberdade acadêmica, de forma que esta é mais ampla que aquela. (TRAVINCAS, 2016, p. 43). Seja qual o posicionamento adotado, importante guardar o uso das expressões como sinônimas, como direito fundamental garantido ao docente, de proporcionar o ensino sem limitações antidemocráticas previamente estabelecidas.
} 
Ato contínuo, a Constituição de 1946 trouxe em seu texto a garantia da liberdade de cátedra como princípio a ser adotado pela legislação de ensino, tema tratado na disposição do inciso VII do artigo 168. (BRASIL, 1946).

Por sua vez, a disposição constitucional do ano de 1967 tratou do tema liberdade de cátedra sob uma perspectiva mais ampla do direito à educação (RODRIGUES; OLIVEIRA, 2019 , p. 165), nos termos do inciso VI, no parágrafo $3^{\circ}$ do artigo 168 , reiterando, do mesmo modo que a constituinte de 1946, a garantia da liberdade de cátedra como princípio adotado na legislação de ensino. (BRASIL, 1967).

A atual Constituição não traz em seu bojo de forma expressa a liberdade de cátedra como direito garantido ${ }^{8}$, no entanto, de acordo com a interpretação que possa ser adotada, pode ser expressa no contexto de outras liberdades, como espécie do gênero liberdade de expressão (artigo $5^{\circ}$ inciso IX), ou traduzida pela expressão liberdade de ensinar, consoante já apresentado, nos termos do artigo 206 inciso II da Constituição Federal de 1988. (RODRIGUES; OLIVEIRA, 2019).

A liberdade acadêmica ou liberdade de cátedra significa atribuir legitimidade ao docente, para que conduza o processo de ensino-aprendizagem de forma críticoepistemológica, sem que haja o cerceamento pelo poder estatal, no sentido de retirar-lhe o poder de debater em sala de aula. Incumbe ao Estado, como órgão responsável por estabelecer diretrizes educacionais, organizar os conteúdos curriculares através de parâmetros gerais, de forma a se padronizar uma estrutura coerente de matriz, de forma que o docente, não ignore ao disposto nos conteúdos pré-estabelecidos, porém, amplamente legitimado para ir além do disposto nos conteúdos. (COSTA, 2018, p. 384).

Logo, conceder a liberdade acadêmica é permitir a ampla discussão pedagógica em conteúdos limitados pelo Poder Público, como forma de padronização, e, para fins de se evitar eventuais excessos e disparidades entre as informações transmitidas. No entanto, pela liberdade, não há como limitar a subjetividade do docente, quando se está atendendo as

\footnotetext{
${ }^{8}$ Em complemento aos esclarecimentos dos termos Liberdade Acadêmica e Liberdade de Cátedra, Rodrigues e Oliveira destacam da importância de não se confundir o significado e alcance das expressões liberdade de cátedra (liberdade acadêmica) e liberdade de expressão: "Essa segunda perspectiva é a aqui adotada, sendo que a partir de agora será utilizada a expressão liberdade acadêmica docente de ensinar para indicar a liberdade atribuída aos professores no âmbito de suas atividades de ensino. Dessa forma se quer deixar claro que a liberdade de cátedra - não mais prevista de forma expressa no texto constitucional - apresenta-se contemporaneamente como a liberdade acadêmica de ensinar do docente, com os limites que lhe impõe os demais princípios, liberdades e garantias vinculadas ao direito fundamental à educação, não podendo em nenhum momento ser confundida com a liberdade ampla de expressão". (RODRIGUES; OLIVEIRA, 2019, p. 166).
} 
normativas educacionais, e, realizando o aporte crítico do conhecimento ${ }^{9}$, de forma equilibrada e com bom senso, na busca do estímulo ao processo de ensino-aprendizagem em favor do aluno.

Nesse contexto, encontram-se de forma paralela a liberdade de cátedra e de ensinar, aliado ao direito do aluno em aprender, sem que se atribua o conhecimento de forma unilateral e forçada, tornando-o em grande parte, responsável pelo diálogo democrático no espaço de aprendizagem ${ }^{10}$.

Portanto, a ideia da liberdade acadêmica se correlaciona com a expressão educação liberal, como um modelo educacional a ser executado de forma livre, denominação oposta ao termo doutrinação qualificada esta, como "[...] a transmissão de concepções acompanhada da supressão da possibilidade de crítica, a redução a zero das condições de consideração de alternativas às ideias apresentadas". (TRAVINCAS, 2016, p. 47).

A participação do professor no processo de ensino aprendizagem deve ser proativa e transformativa, jamais neutra, voltada a ideia de permitir ao docente, um espaço de tráfego, a fim de que o mesmo possa se expressar sobre conteúdos, da maneira que melhor lhe aprouver. (TRAVINCAS, 2016, p. 49-50) ${ }^{11}$.

Neste contexto, cabe ao professor construir e fundamentar suas proposições a partir de conhecimento científico racional, de forma a não profetizar dogmas, tratando do espaço de

\footnotetext{
${ }^{9}$ Epistemologia Critica, em consequência, é o estudo científico e filosófico do conhecimento que têm por objeto o saber científico, técnico, cultural e filosófico de um conjunto autônomo e crítico de práticas (ações) e saberes conscientes baseados em instâncias integradas de mediação (objeto↔sujeito), que sejam: (i) não dogmáticas ou absolutas, mas flexíveis e coletivas, em que todo o objeto do conhecimento pode ser matéria (princípio), instrumento (meio) e produto ou forma (fim); (ii) sem conteúdos prévios, mas construídas através da sistematização das suas relações, do esclarecimento dos seus vínculos, da avaliação dos seus resultados e aplicações; (iii) não hierarquizadas, em que o objeto e o sujeito do conhecimento são mediados e mediadores, em que a alternância e a polivalência do objeto e do sujeito no que se refere à mediação é uma regra e não uma exceção; (iv) baseadas no primado do real concreto sobre o real pensado, com uma necessária integração dinâmica e contraditória entre ambos. (FARIA, 2014, p. 3).

${ }^{10} \mathrm{O}$ ato de ensinar materializa-se no direito de aprender, ou seja, tanto docente quanto discente ensinam e aprendem no âmbito escolar. O docente pode se utilizar de metodologias, estratégias e concepções pedagógicas para trabalhar em sala de aulas análises plurais e transdisciplinares de temas que integram os parâmetros curriculares. (COSTA, 2018, p. 384).

${ }^{11}$ A Autora defende a ideia de segurança do docente no processo de ensino aprendizagem, trazendo a questão do conhecimento específico acerca de um conteúdo, para fazer valer a condição de docente, de forma que, se o docente não se sente à vontade acerca do conteúdo, melhor evitá-lo: “[...] Por maior que seja o ímpeto de horizontalização do ensino - como, de resto, é o que se costuma defender -, é parte do processo educativo que esse papel seja exercido por professores. Parece óbvio que isso não é o mesmo que dizer que professores detêm todo o conhecimento e alunos nenhum. Ademais, caso não se reconheça que professores detêm conhecimento especializado de uma maneira tal que possibilite a ocupação do cargo que ocupam (e que essa condição não detém, ainda, aqueles que figuram como alunos), então o processo educativo se desfragmentaria". (TRAVINCAS, 2016, p. 49).
} 
transmissão do conhecimento e do saber, uma forma de testar conhecimentos científicos, de buscar novos significados a juízos de valores estabelecidos pela doutrina dominante, e mais, rebater de forma crítica e dentro do conhecimento, posicionamentos já apresentados. (COSTA, 2018, p. 386).

Como complemento, a liberdade acadêmica garante a autonomia científica aos professores, permitindo com que se manifestem sobre seus conteúdos de responsabilidade através de seus próprios pontos de vistas, sempre observando o reconhecimento científico de seus argumentos. Permite ainda, a liberdade de escolha do professor, a questões que dizem respeito a didática, atividades, recursos metodológicos, nele incluído a liberdade de escolha de textos e obras dentre aqueles que contemplem no todo ou em parte, o conteúdo a ser ministrado. (RODRIGUES; OLIVEIRA, 2019, p. 166).

Desta forma, ensinar e aprender enquanto liberdades garantidas, apesar de aparentemente se situarem em extremidades distintas de forma abstrata, caminham congregados no processo de ensino-aprendizagem, de forma que um não sobrevive sem o outro. Se de um lado a liberdade acadêmica de ensinar permite ao professor expor de forma democrática seu conhecimento sob um ponto de vista equilibrado e subjetivo, no outro, figura-se a liberdade acadêmica de aprender, tornando-se o discente, ator do processo de aprendizado disponibilizado pelo professor. (RODRIGUES; OLIVEIRA, 2019, p. 167).

Portanto, a construção do processo de ensino-aprendizagem dentro de um Estado Democrático de direito se perfaz através da paridade de armas, de forma que a liberdade de ensinar do professor transmite de forma compulsória, na mesma quantidade e qualidade, a liberdade de aprender do aluno.

\section{A EDUCAÇÃO EM DIREITOS HUMANOS}

Estabelecer aportes teóricos acerca dos direitos humanos é de extrema complexidade. Portanto, pretende-se explorar no presente, as especificidades da expressão educação em direitos humanos, muito embora não se possa deixar de lado a expressão direitos humanos ${ }^{12}$.

\footnotetext{
12 "A construção de um conceito de direitos humanos para a sociedade deve ter como eixo fundamental a dignidade da pessoa humana, visando o integral desenvolvimento de seu potencial criador enquanto cidadão crítico e consciente de seus deveres e direitos. [...] A ideia de Direitos Humanos é relativamente nova na história ocidental. Esses direitos foram conquistados de forma diferente em cada sociedade, e surgiram como alternativa
} 
Quando se fala na expressão educação em direitos humanos ${ }^{13}$, está a se retratar a preocupação com o bem coletivo, de forma que discurso e ação devam ser implementados por todos os envolvidos no processo. Se trata de uma integração de processos de aprendizagem, caracterizada como uma forma de "preparar os indivíduos para que possam participar da formação de uma sociedade mais democrática e mais justa”. (BRASIL, 2013, p. 34).

O Plano de Ação da UNESCO (2006, p. 1) define a educação em direitos humanos como:

“[...] um conjunto de atividades de educação, de capacitação e de difusão de informação, orientadas para criar uma cultura universal de direitos humanos. Uma educação integral em direitos humanos não somente proporciona conhecimentos sobre os direitos humanos e os mecanismos para protegê-los, mas que, além disso, transmite as aptidões necessárias para promover, defender e aplicar os direitos humanos na vida cotidiana. A educação em direitos humanos promove as atitudes e o comportamento necessários para que os direitos humanos de todos os membros da sociedade sejam respeitados.

Em análise a legislação interna, o Plano Nacional de Educação em Direitos Humanos subdivide respectivo conteúdo em cinco temáticas, quais sejam, o estudo da educação em direitos humanos pela Educação Básica, Educação Superior, Educação Não Formal, Educação dos Profissionais dos Sistemas de Justiça e Segurança e a Educação e Mídia. (BRASIL, 2007).

Portanto, conceitua a educação em direitos humanos como "um processo sistemático e multidimensional que orienta a formação do sujeito de direito" (BRASIL, 2007, p. 25), e, para tanto, articula-se sobre as seguintes dimensões:

\footnotetext{
“a) apreensão de conhecimentos historicamente construídos sobre direitos humanos e a sua relação com os contextos internacional, nacional e local; b) afirmação de valores, atitudes e práticas sociais que expressem a cultura dos direitos humanos em todos os espaços da sociedade; c) formação de uma consciência cidadã capaz de se fazer presente em níveis cognitivo, social, ético e político; d) desenvolvimento de processos metodológicos participativos e de construção coletiva, utilizando linguagens e materiais didáticos contextualizados; e) fortalecimento de práticas individuais e sociais que gerem ações e instrumentos em favor da promoção, da
}

para garantir à pessoa, dentro de uma sociedade, as condições essenciais à plenitude do gozo da vida humana". (BRASIL, 2013, p. 16).

${ }^{13}$ A Educação em Direitos Humanos é conceituada por Rodrigues e Lapa (2017, p. 138) de forma ampla, "como o conjunto de ações e práticas educativas - formais e não formais - voltadas à conscientização da sociedade sobre as questões relativas aos Direitos Humanos e à sua organização e participação na defesa dos direitos de todos os humanos. Adotado esse conceito, ela inclui tanto a educação formal, no âmbito dos diversos sistemas de ensino, quanto a educação não-formal, nos âmbitos público e privado". 
proteção e da defesa dos direitos humanos, bem como da reparação das violações. (BRASIL, 2007, p. 25)

Ademais, o Conselho Nacional de Educação aprovou no ano de 2012, as Diretrizes Nacionais para a Educação em Direitos Humanos, editando a Resolução CNE/CP n. 01/2012. O fundamento pauta-se na dignidade da pessoa humana caracterizando nos termos do artigo $2^{\circ}$ "a Educação em Direitos Humanos, um dos eixos fundamentais do direito à educação", materializada na utilização de ideias, criações e práticas educativas nos direitos humanos, buscando-se através de determinados processos, promover, proteger, defender e aplicar os direitos humanos no cotidiano dos sujeitos de direitos, responsáveis individuais e coletivos de tais direitos. (BRASIL, 2012).

Em específico, o artigo $3^{\circ}$ da respectiva Resolução aponta como princípios fundamentais na finalidade de promover a educação em direitos humanos com vias a mudança e transformação social, a dignidade da pessoa humana (inciso I), a igualdade de direitos (inciso II), o reconhecimento e valorização das diferenças e das diversidades (inciso III), a laicidade do Estado (inciso IV), a democracia na educação (inciso V), a sustentabilidade socioambiental (inciso VII), e em destaque, a transversalidade, vivência e globalidade (inciso VI). (BRASIL, 2012).

Desta forma, percebe-se que a Educação em Direitos Humanos é vista sobre três eixos que se complementam entre si: a) a visão da Educação em Direitos Humanos como educação para a cidadania, seja legislação internacional e interna; b) a obrigatoriedade de seu estudo para aqueles que estão se preparando para a docência ${ }^{14}$; e, c) a Educação em Direitos Humanos como espaço de formação técnica dos defensores dos Direitos Humanos e outros operadores do Direito, bem como todos aquelas que fazem parte dos sistemas de justiça e segurança. (RODRIGUES; LAPA, 2017, p. 135).

Sendo assim, a educação em direitos humanos é prática promocional, preventiva e participativa dos indivíduos e da coletividade, e, que por parte do Estado, deve ser obrigatoriamente incentivada, seja pela educação, pela cultura, através da adoção de políticas públicas e da atuação conjunta do Poder Público em todas as searas de atuação.

\footnotetext{
${ }^{14}$ A exigência de aporte técnico por parte dos docentes encontra respaldo na Resolução n. 1/2012, que estabelece as Diretrizes Nacionais para a Educação em Direitos Humanos: “Art. $8^{\circ}$ A Educação em Direitos Humanos deverá orientar a formação inicial e continuada de todos(as) os(as) profissionais da educação, sendo componente curricular obrigatório nos cursos destinados a esses profissionais". (BRASIL, 2012).
} 


\subsection{A EDUCAÇÃO EM DIREITOS HUMANOS NO ENSINO SUPERIOR: UMA ABORDAGEM NO ENSINO JURÍDICO}

Inicialmente, o marco de delimitação legislativa no ensino superior encontra-se previsto na Constituição Federal, quando garante a autonomia universitária de natureza didática, científica, administrativa, financeira e patrimonial, observando-se a regra indissociável entre pesquisa, ensino e extensão. (BRASIL, 2007, p. 37).

A normativa que norteia a aplicação da Educação em Direitos Humanos internamente, especialmente no que diz respeito ao Ensino Superior, são as Resoluções que instituem as Diretrizes Curriculares ${ }^{15}$, aplicáveis a cada especificidade de curso de graduação nas áreas da tecnologia, bacharelado e licenciaturas.

No ensino jurídico, vale destacar a Resolução n. 5 de $2018^{16}$ que institui as Diretrizes Curriculares do Curso de Graduação em Direito e dá outras providências, atento ao disposto no artigo $2^{\circ} \S 4^{\circ}$, que demonstra de forma expressa quais as informações indispensáveis constantes de um Projeto Pedagógico de $\mathrm{Curso}^{17}$ :

\footnotetext{
Art. $2^{\circ}$ No Projeto Pedagógico do Curso (PPC) deverão constar:

[...]

$\S 4^{\circ} \mathrm{O}$ PPC deve prever ainda as formas de tratamento transversal dos conteúdos exigidos em diretrizes nacionais específicas, tais como as políticas de educação ambiental, de educação em direitos humanos, de educação para a terceira idade, de educação em políticas de gênero, de educação das relações étnico-raciais e histórias e culturas afro-brasileira, africana e indígena, entre outras.
}

\footnotetext{
15 “A expressão diretrizes curriculares foi utilizada pela primeira vez no Direito Educacional brasileiro na Portaria MEC n. 1.886/1994. Posteriormente, a competência para sua definição foi atribuída, pela Lei n. 9.131/1995, à Câmara de Educação Superior do Conselho nacional de Educação (CES/CNE). As diretrizes curriculares são as orientações geais definidas pelo órgão juridicamente competente e devem ser cumpridas pelas IES na elaboração dos projetos pedagógicos e currículos plenos de seus cursos. Nelas, está contida a exigência da elaboração do PPC e enumerados os elementos que o compõem”. (RODRIGUES, 2020, p. 24).

${ }^{16}$ A Resolução foi aprovada por Parecer 635/2018 do Conselho Nacional de Educação/Câmara de Educação Superior (CNE/CES), favorável a revisão das Diretrizes Curriculares Nacionais do curso de Graduação em Direito. (BRASIL, 2018).

Em destaque, como reforma as Diretrizes anteriores, a inclusão das atividades que envolvem os métodos alternativos de solução de conflito, presente no artigo $3^{\circ}$ (perfil do graduando - domínio das formas consensuais de composição de conflitos), as competências cognitivas previstas no artigo $4^{\circ}$ inciso VI (desenvolver a cultura do diálogo e o uso de meios consensuais de solução de conflitos), e a necessária inclusão ao PPC, de conteúdosatividades na formação técnico-jurídica das formas consensuais de solução de conflitos (art. 5 II). (BRASIL, 2018a).

${ }^{17} \mathrm{O}$ projeto pedagógico constitui-se no planejamento que uma IES faz para um determinado curso. Nele, além de conteúdos e competências, distribuídos nas disciplinas ou módulos e nas atividades que compõem o currículo pleno, é necessário indicar também como serão trabalhados, efetivamente, durante o desenvolvimento do curso, os diversos componentes curriculares. (RODRIGUES, 2020, p. 26).
} 
A Diretriz curricular em apreço exige do perfil $^{18}$ do graduando em direito sólida formação geral e humanística, o que justifica a ideia de aplicação da educação em direitos humanos sob uma análise do ensinar e do aprender.

Ainda, a educação em direitos humanos para o ensino jurídico superior pode ser visualizada sobre três propósitos, dos quais destacam-se: a) a informação e conhecimento dos direitos humanos na construção histórica, bem como a importância da denominação e significado (reconhecimento como sujeito de direitos); b) a formação de futuros profissionais e defensores dos direitos humanos, protagonistas das mudanças propostas (preparo técnico no processo de garantia e ampliação dos direitos humanos); e, c) o aprofundamento e reciclagem do conhecimento específico sobre os direitos humanos para atuais defensores (formação continuada para aqueles que trabalham com direitos humanos). (RODRIGUES; LAPA, 2017, p. 154-155).

Em razão disto, a bem da legitimação e efetividade dos direitos humanos, a expressão não pode ser aplicada como disfarce em sala de aula, tornando-se indispensável uma modificação brusca e necessária na utilização da expressão em suas inúmeras vertentes (cultural, ética, social, humanitária), possibilitando que se vá além de uma mera disciplina do curso, para que assim, se possa atingir os pilares de todo e qualquer ordenamento. (MAROCCO, 2017, p. 59).

Portanto, aos estudiosos da ciência jurídica, a tarefa de implantação prática do estudo dos direitos humanos sob várias vertentes, em todas as áreas do direito é consciência que deve ser tomada de imediato, uma vez que o pensamento jurídico requer a apreciação delicada nesta área do conhecimento, pois, interligada em vários ramos da ciência jurídica. Este liame dos direitos humanos com vários ramos do direito, que justifica o seu estudo pela transversalidade.

\section{A LIBERDADE ACADÊMICA NA EDUCAÇÃO EM DIREITOS HUMANOS: UMA PROPOSTA DE ESTUDO À PARTIR DA TRANSVERSALIDADE}

\footnotetext{
${ }^{18}$ As DCNs definem um perfil amplo que deve ser buscado por todos os cursos de graduação em Direito do país. $\mathrm{O}$ perfil indicado demonstra claramente a necessidade de direcionar os cursos para o desenvolvimento de competências e não apenas para a apreensão de conteúdos. [...] Cada IES, em seu PPC, poderá acrescentar, ao perfil indicado nas DCNs, aspectos atinentes a sua própria proposta, considerando a concepção, os objetivos e a vocação de seu curso, sem, entretanto, descurar-se do perfil nacionalmente definido. (RODRIGUES, 2020, p. 53$54)$.
} 
Antes de se adentrar ao propósito de delimitação do tema, é indispensável estabelecer os traços distintivos em relação as expressões multidisciplinaridade e transdisciplinaridade no ensino.

$\mathrm{Na}$ expressão multidisciplinaridade ${ }^{19}$ para o ensino, os conteúdos e atividades são trabalhados de forma independente, de forma que não há como se visualizar a relação entre elas. No campo da pesquisa, se manifesta quando se recorre a disciplinas diversas para se conhecer o significado de cada uma delas sobre o mesmo objeto de estudo. (RODRIGUES; LAPA, 2017, p. 143).

Por sua vez, a interdisciplinaridade ${ }^{20}$ permite o intercâmbio (diálogo) entre as disciplinas com o objetivo primordial de aproximação a realidade, de forma que enfrente a realidade e problemas efetivos. Por tal prática, permite-se analisar sobre extremidades, de um lado, os limites do sujeito que constrói o conhecimento acerca de uma realidade, e, de outro, a diversidade e pluralismo desta mesma realidade. (RODRIGUES; LAPA, 2017, p. 144).

A transdisciplinaridade como traço distintivo vai além dos conceitos apresentados. Pretende-se produzir algo novo ao contexto da realidade, além do que as disciplinas prescrevem. Portanto, busca através do choque das disciplinas, novos dados e informações que as articulam entre si, proporcionando uma nova perspectiva e visão sobre o objeto estudado. (RODRIGUES; LAPA, 2017, p. 144).

Logo, multidisciplinar é o estudo de várias disciplinas, de forma que se alcance o significado sobre um mesmo objeto estudado. A interdisciplinaridade traz consigo o uso das várias disciplinas de forma prática próximo a realidade com vias a resolução de problemas. Ao fim, a transdisciplinaridade guarda a característica de estudo além de seus significados, de forma que o cientista da área possa explorar a partir de seus significados já contextualizados, novos aportes teóricos e conclusões (quebra de paradigmas).

\footnotetext{
${ }^{19}$ A conclusão disposta por Rodrigues e Lapa (2017, p. 143-144) deixa clarividente seu significado: [..] "Ou seja, a multidisciplinaridade indica a necessidade de conhecer os diferentes conceitos de um mesmo objeto segundo diferentes disciplinas. Mas não indica nenhuma preocupação de integração de seus pontos comuns, articulando as perspectivas das diversas disciplinas".

${ }^{20}$ Para melhor delimitação dos significados, Rodrigues e Lapa (2017, p. 144) diferenciam a inter da transdisciplinaridade: "A diferença entre a inter e a transdisciplinaridade é que a transdisciplinaridade não se resume na colaboração das disciplinas entre si, mas sim na construção de um pensamento complexo organizador, que vai além dessas disciplinas. Já na interdisciplinaridade o que se efetua é uma permuta de conhecimentos, sendo portanto, em tese, menos integradora - mas mais realista - que a transdisciplinaridade".
} 
Estabelecida as distinções, a educação em direitos humanos tratada sob a forma de eixo transversal ${ }^{21}$ deve ser analisada sob o ponto de vista sistêmico, possibilitando a evolução do conhecimento através do aprendizado sobre diferentes técnicas e discussões, de forma a superar a barreira de noções conceituais, fundamentos e técnicas da disciplina, matéria ou área do conhecimento. (RODRIGUES; LAPA, 2017, p. 145).

Neste sentido, liberdade acadêmica na educação em direitos humanos deve ser vista no ensino superior, especialmente no ensino jurídico, de forma transversal, em virtude da amplitude do significado e alcance da expressão direitos humanos.

A transversalidade como dito, é aplicar sobre diversas disciplinas e conteúdos, a relação devida com os direitos humanos, seja pelo aspecto ético, de cidadania, jurídico ou social, de forma a convergir o instituto dentre vários significados, ampliando conhecimento do aluno sobre várias vertentes (ramos do direito).

Não há como se pensar de forma isolada, por exemplo, o trabalho escravo, sem que se correlacione com as disciplinas e conteúdos do direito do trabalho, processo do trabalho, direito penal, direito constitucional e direitos humanos. $\mathrm{O}$ assunto converge com todas as disciplinas dada a sua amplitude, e, de forma prática, através do estudo de casos, resolução de problemas, tais situações colocadas em prática de forma simulada ou real, trazem à tona, a fiel execução da prática da educação em direitos humanos sobre várias concepções.

A título de ilustração, extrai-se uma proposta apresentada a Universidade Federal de Minas Gerais, para a formação complementar na graduação em direitos humanos ${ }^{22}$, distribuída em 360 horas de carga horária, com disciplinas a serem cursadas de forma obrigatória. A curiosidade que trouxe para fins de transcrição no trabalho, é o fato da diversidade de módulos trabalhados de forma transversal e que tratam sobre direitos humanos.

\footnotetext{
${ }^{21}$ A utilização da transversalidade na educação em direitos humanos é defendida por Rodrigues e Lapa (2017), pela adoção de uma metodologia do projeto denominada planejamento em rede, de forma que o projeto deva ser estudado com vias a solução de determinado problema local ou regional. Respectiva metodologia tem por fim a integração de vários saberes e possibilita a utilização de um trabalho que não se resuma a teoria como estudo, mas a análise prática das circunstâncias e realidades locais e regionais, para efeito de resolução do problema.

${ }^{22}$ O Proponente é a Rede de Direitos Humanos da UFMG, iniciativa da Pró-Reitoria de extensão: na proposta é visível a preocupação institucional na construção de uma política de intensificação em prol dos direitos humanos no intuito de fortalecer na comunidade acadêmica o respeito a diversidade, igualdade, inclusão e cidadania. Mais ainda, o destaque ao perfil do egresso: "[...] Esperamos que a/o estudante que tenha realizado a Formação Transversal em Direitos Humanos seja capaz de reconhecer e refletir sobre questões chave que envolvem os direitos humanos em diferentes campos disciplinares articulando a sua dimensão mais formal com aspectos da vida cotidiana. Além disso, buscamos através da formação, apresentar e construir ferramentas e fortalecer competências que permitam à/ao estudante identificar os efeitos das práticas profissionais no enfrentamento às violações de direitos humanos, possibilitando que o/a mesmo/a, entre muitas funções, possa atuar criticamente como um/a interlocutor/a entre as políticas públicas estatais e os movimentos sociais". (BRASIL, 2016).
} 
Distribui-se o trabalho em 11 módulos com carga horária entre 30 e 60 horas distribuídas sobre três eixos a saber: 1) o estudo dos fundamentos históricos e filosóficos dos direitos humanos a partir do histórico e fundamentos para construção dos marcos regulatórios e dos instrumentos de proteção e da organização e lutas dos movimentos sociais, 2) o estudo dos direitos humanos no Brasil e 3) a relação dos direitos humanos com as políticas públicas. (BRASIL, 2016).

Os módulos das disciplinas são ministrados sobre as seguintes temáticas: as lutas sociais (lutas de classes); os instrumentos de proteção (Direito Internacional aplicado); a desigualdade entre Estado e Sociedade; a Democracia e o Estado Laico; práticas políticas e de intervenção nos direitos humanos; Políticas Públicas; Gênero e sexualidade; Infância, Adolescência e Juventude; relações étnico-raciais; memória, verdade e Justiça; Direitos da pessoa idosa, moradia, trabalho e direitos, internet; Saberes Tradicionais; cultura afrobrasileira, história da África. (BRASIL, 2016).

Pelo que se depreende do contexto da exemplificação acima, observa-se a relação dos módulos propostos com várias disciplinas tradicionais de formação geral e técnico jurídica previstas na Resolução que trata das Diretrizes Curriculares do Curso de Graduação em Direito. O elo de transversalidade dos módulos na formação geral com a Sociologia, Ciência Política, Ética, Antropologia e História é indispensável, uma vez que, as disciplinas são convergentes quando se trata do estudo da educação em direitos humanos. Ademais, no eixo de formação técnico-jurídica, a Teoria do Direito, o Direito Constitucional, Direito Penal, Direito do Trabalho, Direito de Família, e, do mesmo modo, as formas consensuais de solução de conflitos se convergem para fins de aplicação da transversalidade na educação em direitos humanos.

Portanto, falar em transversalidade a partir da liberdade acadêmica na educação em direitos humanos é quebrar o paradigma de que as disciplinas conversam somente quando se trata da relação entre direito material e processo. A transversalidade deve ser provocada pelo professor, sujeito ativo do processo de transformação do aprendizado na educação em direitos humanos.

A liberdade acadêmica parte da premissa do direito de ensinar dentro de qualquer restrição ou opressão estatal, mas acima de tudo, o respeito recíproco da liberdade de aprender. Ao professor, indispensável que tenha conhecimento da importância enquanto 
formação de opinião aos seus ouvintes, que lhe atribuem uma confiança tal, ao ponto de se tornarem seguidores e admiradores no mundo real, e, na atualidade, no mundo virtual.

Neste sentido, defende-se que a transversalidade parte do professor, responsável pelo processo dialético com outro professor, de disciplina convergente ou até mesmo divergente, uma vez que, a transversalidade em grande parte se inicia a partir de um problema que deva ser desvendado cientificamente através do raciocínio no aprender, e nos debates e discussões entre o ensinar e o aprender.

Por fim, defende-se a comunicação explícita dos sujeitos que participam do processo de ensino-aprendizagem, especialmente dos responsáveis pela iniciativa das discussões, o professor. É o docente que tem de visualizar de forma transversal, para além dos conteúdos, costumeiramente ministrados através de conceitos e fundamentos dogmatizados ${ }^{23}$. O diálogo entre disciplinas, especialmente na conversa das disciplinas para a educação em direitos humanos é ferramenta que deve ser aplicada para a criação, proteção e promoção na educação em direitos humanos.

\section{CONCLUSÃO}

Conclui-se em suma que a educação como direito fundamental social é direito de todos, e imposição positiva perante o Estado enquanto necessária disponibilização do acesso, e, principalmente, da ampliação da oferta em favor da população.

A Liberdade de ensinar e a liberdade acadêmica, seja qual for o posicionamento adotado, provoca a necessidade de conceder a todos, a liberdade de ensinar, sempre correlacionada com a liberdade de aprender, atribuindo como direito constitucional, a autonomia universitária as Instituições de Ensino Superior, com a característica da indissociabilidade entre pesquisa, extensão e ensino.

Desta forma, a liberdade de ensinar, enquanto direito constitucional garantido, proporciona ao livre docente o direito de apresentar seus conteúdos, posicionamentos, ideias e discussões, sem que haja a interferência e restrição (censura estatal). Por ser parte do processo

\footnotetext{
${ }^{23}$ Neste sentido: É através da liberdade de pensamento cientifico que o docente retira o discente da "zona de conforto", apontando as aporias, estimulando o pensamento multicêntrico, demonstrando que o pensamento cientifico assegura aos indivíduos liberdade e lucidez ao conseguir compreender o mundo para além da irracionalidade advinda de fé. Por isso, em qualquer sociedade que se pretende ver construída em bases democráticas, jamais se deve admitir qualquer postura estatal no sentido de calar, silenciar, amordaçar, seja de forma velada ou explicita, a pessoa do professor. (COSTA, 2018, p. 388).
} 
do direito constitucional a educação, por certo, encontra-se limitado ao disposto nas normativas educacionais, para fins de se evitar exageros, e propósitos de conteúdos distintos ou fora da disciplina/conteúdo a ser ministrado.

Neste sentido, o professor na liberdade de ensinar, não fica restrito a dogmas e conhecimentos petrificados na transmissão do saber. Em conjunto com o aluno, torna-se indispensável que a pedra seja desbastada e moldurada, levando em consideração posicionamentos dialéticos e críticos na construção do saber. É necessário que fique claro, que o professor na liberdade acadêmica esteja desprovido de convicções religiosas, políticas, de forma a se evitar o discurso em sala de aula parcial e tendencioso. Tal situação provoca por óbvio a quebra do direito constitucional da liberdade de aprender e ensinar.

Ressalta-se, a liberdade acadêmica na educação em direitos humanos requer em um Estado Democrático de Direito, um espaço físico capaz de discussões igualitárias entre docentes e discentes, através de uma construção discursiva do conhecimento. Diante disto, é preciso de ambos os lados, que se tenha consciência de que o conhecimento é ilimitado, o respeito ao diálogo crítico em ambas as extremidades (ensinar e aprender), a repreensão a toda a forma discriminação, a aceitação das inovações, falar cientificamente, mas principalmente ouvir as propostas do diálogo de forma democrática.

Por fim, falar em liberdade acadêmica na educação em direitos humanos, em especial no ensino superior no Direito é buscar o aprofundamento do conhecimento através de estudos transversais, de forma a estimular o pensamento crítico do aluno, nas diferentes áreas do ensino, da extensão e da pesquisa.

No entanto, antes de se propor qualquer estudo transversal, indispensável que as pessoas conheçam dos direitos, a história e a evolução, mas principalmente, a prática dos direitos humanos no dia-dia, seja sobre o aspecto ético, social, cultural e de cidadania. De nada adianta aprofundar conhecimento, se as atitudes não são desenvolvidas e praticadas cotidianamente.

\section{REFERÊNCIAS}

ASSEMBLEIA GERAL DA ONU. Declaração Universal dos Direitos Humanos. 10 dez. 1948. Disponível em: https://nacoesunidas.org/wp-content/uploads/2018/10/DUDH.pdf. Acesso em: 25 jan. 2020. 
BONAVIDES, Paulo. Curso de Direito Constitucional. 25 ed. atual. São Paulo: Malheiros Editores, 2010.

BRASIL. Constituição da República dos Estados Unidos do Brasil de 16 de Julho de 1934. Disponível em: http://www.planalto.gov.br/ccivil_03/constituicao/constituicao34.htm. Acesso em: 21 jan. 2020.

. Constituição dos Estados Unidos do Brasil de 18 de Setembro de 1946. Disponível em: http://www.planalto.gov.br/ccivil_03/constituicao/constituicao46.htm Acesso em: Acesso em: 25 jan. 2020.

Constituição da República Federativa do Brasil de 1967. Disponível em: http://www.planalto.gov.br/ccivil_03/constituicao/constituicao67.htm Acesso em: Acesso em: 25 jan. 2020.

. Constituição da República Federativa do Brasil de 1988. Disponível em: < http://www.planalto.gov.br/ccivil_03/Constituicao/Constituicao.htm> . Acesso em: 25 jan. 2020.

Lei $n^{\circ} 9.394$ de 20 de Dezembro de 1996. Estabelece as diretrizes da educação nacional. Disponível em: http://www.planalto.gov.br/ccivil_03/leis/19394.htm. Acesso em: Acesso em: 25 jan. 2020.

. Lei $\mathbf{n}^{\circ}$ 10.172 de 9 de Janeiro de 2001. Aprova o Plano Nacional de Educação e dá outras providências. Disponível em: http://www.planalto.gov.br/ccivil_03/leis/leis_2001/110172.htm. Acesso em: 25 jan. 2020.

Resolução CNE/CES n. 5, de 17 de dezembro de 2018. Institui as Diretrizes Curriculares Nacionais do Curso de Graduação em Direito. Disponível em: http://portal.mec.gov.br/component/content/article?id=12991. Acesso em: 01 fev. 2020.

. Parecer CNE/CES n. 635/2018, aprovado em 4 de outubro de 2018. Revisão das Diretrizes Curriculares Nacionais do curso de Graduação em Direito. Disponível em: http://portal.mec.gov.br/component/content/article?id=12991. Acesso em: 01 fev. 2020.

. Ministério da Educação. Conselho Nacional de Educação. Resolução n. 01 de 30 de maio de 2012. Estabelece Diretrizes Nacionais para a Educação em Direitos Humanos. Disponível em: http://portal.mec.gov.br/dmdocuments/rcp001_12.pdf. Acesso em: 21 jan. 2020.

Secretaria de Direitos Humanos da Presidência da República. Educação em Direitos Humanos: Diretrizes Nacionais - Brasília: Coordenação Geral em Educação em 
SDH/PR, Direitos Humanos, Secretaria Nacional de Promoção e Defesa dos Direitos Humanos, 2013.

Disponível

em:

http://portal.mec.gov.br/index.php?option=com_docman\&view=download\&alias=32131educacao-dh-diretrizesnacionais-pdf\&Itemid=30192. Acesso em: 21 jan. 2020.

Comitê Nacional de Educação em Direitos Humanos. Plano Nacional de Educação em Direitos Humanos. Brasília: Secretaria Especial dos Direitos Humanos, UNESCO, 2007. Disponível em: http://portal.mec.gov.br/docman/2191-plano-nacional-pdf/file. Acesso em: 25 jan. 2020 .

. Universidade Federal de Minas Gerais. Rede de Direitos Humanos da UFMG. Proposta: Formação Transversal em Direitos Humanos, 2016. Disponível em: file://C:/Users/Alexandre/Downloads/Formacao\%20Transversal\%20Direitos\%20Humanos.p $\underline{\mathrm{df}}$

COSTA, Fabrício Veiga. Liberdade de Cátedra do docente nos cursos de bacharelado em direito: um estudo crítico da constitucionalidade do projeto de Lei escola sem partido. Revista Jurídica, Curitiba, Unicuritiba, v. 50, n. 1, 2018, p. 374-397. Disponível em: http://revista.unicuritiba.edu.br/index.php/RevJur/article/view/2555. Acesso em 20 jan. 2020. DUARTE, Clarice Seixas. A Educação como um Direito Fundamental de Natureza Social. Educação \& Sociedade, Campinas, UNICAMP, v. 100, n. 28. Disponível: http://www.scielo.br/pdf/es/v28n100/a0428100. Acesso em: 25 jan. 2020.

DURHAM, Eunice Ribeiro. A autonomia universitária: o princípio constitucional e suas implicações. NUPES - Núcleo de Pesquisas sobre Ensino Superior Universidade de São Paulo e Departamento de Antropologia - FFLCH, disponível em <http://nupps.usp.br/downloads/docs/dt8909.pdf>. Acesso em: 22 jan. 2020.

FARIA, José Henrique de. A Epistemologia Crítica e os Momentos da Pesquisa: uma proposição para os Estudos Organizacionais. Disponível em: http://www.anpad.org.br/admin/pdf/2014_EnEO97.pdf. Acesso em: 25 jan. 2020.

HAYEK, Friedrich August Von. Os Fundamentos da Liberdade. Supervisão e Introdução de Henry Maksoud. Tradução de Anna Maria Capovilla e José Ítalo Stelle. São Paulo: Visão, 1983.

MAROCCO, Andréa de Almeida Leite. Educação para os direitos humanos e o problem based learning: o empoderamento do indivíduo com base no ensino jurídico crítico e reflexivo. Anais do II Encontro Brasileiro Pesquisa, Educação e Epistemologia Jurídica 
[recurso eletrônico] / Andréa de Almeida Leite Marocco, Horácio Wanderlei Rodrigues (Orgs.). ed. rev. e atual. Chapecó: Argos, 2017.

RODRIGUES, Horácio Wanderlei. Cursos de Direito no Brasil: diretrizes curriculares e projeto pedagógico. 2. ed. rev. e atual. Florianópolis: Habitus, 2020.

O direito educacional brasileiro e o alcance da garantia constitucional da liberdade de ensinar. In: FERREIRA, Dâmares (coord.). Direito Educacional: temas educacionais contemporâneos. Curitiba: CRV, 2012. p. 135-148. Disponível em: https://abmes.org.br/arquivos/documentos/hwr_artigo2012-liberdadedeensinar_crv3.pdf.

Acesso em: 21 jan. 2020.

. Direito à educação: acesso, permanência e desligamento de alunos do ensino superior.

Sequência, Florianópolis, UFSC, v. 27, n. 52, p. 201- 2016, jul. 2006. Disponível em:

https://periodicos.ufsc.br/index.php/sequencia/article/view/15207. Acesso em: 28 jan. 2020.

RODRIGUES, Horácio Wanderlei; OLIVEIRA, Amanda Muniz. A Liberdade Acadêmica no

Direito Brasileiro: Fundamento e Abrangência. Revista Opinião Jurídica, Fortaleza, Unichristus, ano 17, n. 25. maio.-ago. 2019, p. 158-176. Disponível em: https://faculdadechristus.academia.edu/Opini\%C3\%A3oJur\%C3\%ADdica. Acesso em $31 / 01 / 2020$.

RODRIGUES, Horácio Wanderlei; LAPA, Fernanda Brandão. O que é ensinar direitos humanos? A educação em direitos humanos e suas diferentes nuances: Formar o cidadão, formar o professor, formar o jurista. Anais do II Encontro Brasileiro Pesquisa, Educação e Epistemologia Jurídica [recurso eletrônico] / Andréa de Almeida Leite Marocco, Horácio Wanderlei Rodrigues (Orgs.). ed. rev. e atual. Chapecó: Argos, 2017.

RODRIGUES, Horácio Wanderlei; MAROCCO, Andréa de Almeida Leite. Liberdade de cátedra e a Constituição Federal de 1988: alcance e limites da autonomia docentes. In: CAÚLA, Bleine Queiroz et al. Diálogo ambiental, constitucional e internacional. Fortaleza: Premius, 2014. v. 2. p. 213-238.

SILVA, José Afonso da. Curso de Direito Constitucional Positivo. 34 ed. rev. e atual. até a Emenda Constitucional n. 67, de 22.12.2010. São Paulo: Malheiros Editores, 2011.

TRAVINCAS, Amanda Costa Thomé. A Tutela Jurídica da Liberdade Acadêmica no Brasil. A Liberdade de Ensinar e seus Limites. 2016. 300 f. Tese de Doutorado. Pontifícia Universidade Católica do Rio Grande do Sul, Porto Alegre, 2016. Disponível em: http://tede2.pucrs.br/tede2/handle/tede/7258. Acesso em 31 jan. 2020. 
UNESCO. Plano de ação: programa mundial para educação em direitos humanos - primeira etapa. Nova York e Genebra, 2006. Disponível em: <http://migre.me/qWy60>. Acesso em: 21 jan. 2020. 